УДК 502.132(470.54-25)

ОРГАНИЗАЦИЯ МОНИТОРИНГА НАСАЖДЕНИЙ

В ЛЕСОПАРКАХ ГОРОДА ЕКАТЕРИНБУРГА

С ПРИМЕНЕНИЕМ МАТЕМАТИКО-СТАТИСТИЧЕСКИХ МЕТОДОВ

\author{
Суслов А.В., Нагимов 3.Я., Корелина А.А. \\ ФГБОУ ВО «Уральский государственный лесотехнический университет», \\ Екатеринбург, е-mail:suslovav@m.иsfeu.ru
}

Статья посвящена обоснованию возможности использования для мониторинга насаждений в лесопарках математико-статистических методов, на которых базируется государственная инвентаризация лесов. С использованием материалов последнего лесоустройства по Единой схеме стратификации лесов Российской Федерации в лесопарках города выделены 29 лесных страт. Установлено, что на долю четырёх основных лесных страт $(4,10,11$ и 37$)$ приходится более $62 \%$ от общей площади лесопарков. Лесные страты существенно различаются по средней продуктивности и в меньшей степени - по изменчивости запасов. Согласно имеющимся в специальной литературе критериям выделенные в лесопарках лесные страты по запасам древесины относятся к однородным и очень однородным лесным массивам. Исследуемые лесопарки отличаются между собой как по средней продуктивности отдельно взятых страт, так и по изменчивости запасов их насаждений. Для выделенных страт по методике государственной инвентаризации лесов определено необходимое количество пробных площадей для организации в них оценочных и мониторинговых исследований. В соответствии с алгоритмом расчёта итоговое количество пробных площадей по отдельным стратам зависит от их однородности по запасам. Поэтому страты из-за разницы в площадях существенно различаются по плотности территориального размещения пробных площадей. Корректное распределение общего количества пробных площадей страты по отдельным лесопаркам возможно на основе удельного веса лесопарков по площади данной страты. Сделан вывод, что для лесопарков актуальна более дифференцированная стратификация насаждений. Выделяемые по Единой схеме страты в лесопарках необходимо разделить на более однородные части (подстраты) с учётом показателей, определяющих жизненное состояние и экологические функции насаждений. Такими показателями, безусловно, являются полнота, возраст и порода (преобладающая порода).

Ключевые слова: лесопарк, стратификация, лесные страты, изменчивость запаса, пробная площадь

\title{
ORGANIZATION OF MONITORING OF PLANTINGS IN FOREST PARKS OF THE CITY OF YEKATERINBURG WITH THE USE OF MATHEMATICAL AND STATISTICAL METHODS
}

\author{
Suslov A.V., Nagimov Z.Ya., Korelina A.A. \\ Ural State Forestry University, Yekaterinburg, e-mail: suslovav@m.usfeu.ru
}

\begin{abstract}
The article is devoted to the substantiation of the possibility of using mathematical and statistical methods for monitoring plantings in forest parks, on which the state forest inventory is based. Using the materials of the latest forest management according to the Unified Scheme of forest stratification of the Russian Federation, 29 forest strata were identified in the city's forest parks. It is established that the four main forest strata $(4,10,11$ and 37$)$ account for more than $62 \%$ of the total area of forest parks. Forest strata differ significantly in average productivity and, to a lesser extent, in stock variability. According to the criteria available in the special literature, the forest countries allocated in forest parks by wood reserves belong to homogeneous and very homogeneous woodlands. The studied forest parks differ from each other both in the average productivity of individual strata, and in the variability of the stocks of their plantations. For the selected strata, according to the methodology of the state forest inventory, the necessary number of test areas for the organization of evaluation and monitoring studies in them is determined. In accordance with the calculation algorithm, the total number of test areas for individual strata depends on their uniformity in reserves. Therefore, the strata, due to the difference in areas, differ significantly in the density of the territorial placement of the sample areas. The correct distribution of the total number of sample areas of the stratum by individual forest parks is possible on the basis of the specific weight of forest parks in the area of this stratum. It is concluded that a more differentiated stratification of plantings is relevant for forest parks. The strata allocated according to a single scheme in forest parks should be divided into more homogeneous parts (sub-strata), taking into account the indicators that determine the vital state and ecological functions of plantings. Such indicators, of course, are fullness, age and breed (the predominant breed).
\end{abstract}

Keywords: forest park, stratification, forest strata, reserve variability, trial area

Лесопарки муниципального образования (МО) «город Екатеринбург» - важнейшая часть экологического каркаса города. Они, выполняя разнообразные экологические и социальные функции, формируют условия жизни человека в мегаполисе. Полезные функции лесных насаждений определяются их количественными и ка- чественными характеристиками. Поэтому эффективность ведения хозяйства в лесопарках города во многом зависит от степени изученности лесоводственно-таксационных и ландшафтных показателей насаждений, их устойчивости и жизненного состояния.

В нашей стране основные сведения о лесах получают при лесоустройстве, которое 
проводится с периодичностью 10 и более лет. Городские леса находятся под постоянным влиянием различных антропогенных факторов, которые определяют специфические особенности роста, ухудшают состояние, снижают устойчивость насаждений. Поэтому здесь материалы лесоустройства, получаемые с определенной периодичностью и характеризующиеся невысокой точностью, не могут являться надежной основой для осуществления лесохозяйственных и лесопарковых мероприятий.

В лесопарках актуальной задачей является организация постоянного мониторинга за ростом и состоянием насаждений. На наш взгляд, перспективным подходом при выполнении этой задачи может являться применение математико-статистическим методов, на которых базируется государственная инвентаризация лесов (ГИЛ) [1].

В настоящее время при проведении ГИЛ в России используется метод случайного размещения пробных площадей, что, по работам некоторых исследователей, является неоптимальным. Преимущества регулярного размещения постоянных кластеров по территории заключаются в более полном покрытии территории [2]. Применение математико-статистических методов при изучении лесов и организации мониторинга требует специальных исследований.

Цель исследования: оценка возможности применения методических рекомендаций по проведению ГИЛ для организации мониторинга насаждений в лесопарках, формирование (выделение) лесных страт и определение количества пробных площадей в них с соблюдением требований к случайной выборке.

Непрерывный мониторинг за лесными насаждениями лесопарков в первую очередь необходим для своевременного выявления и прогнозирования развития процессов, негативно воздействующих на лесные экосистемы и оценки изменений состояния лесов под воздействием антропогенных факторов.

\section{Материалы и методы исследования}

В основу исследований положены методические рекомендации по проведению ГИЛ [1]. В основе ГИЛ лежат математикостатистические методы исследования, основанные на теории вероятностей и законах математической статистики [3, 4]. При этом под генеральной совокупностью понимают все леса, расположенные на территории объекта исследований, а под выборочной статистически репрезентативную часть ге- неральной совокупности, при оценке которой получают необходимую информацию обо всей генеральной совокупности. Метод основан на рациональном сочетании случайной и систематической выборок.

Выборочную совокупность представляют пробные площади. Для получения статистически достоверных результатов по генеральной совокупности с заданной точностью они закладываются с учётом специальных требований к объему выборочной совокупности, случайности ее формирования и репрезентативности.

При проведении ГИЛ для уменьшения количества закладываемых пробных площадей производится стратификация исследуемой территории путем группировки лесных насаждений в более однородные группы (лесные страты). При этом исходят из того, что в выделяемых стратах изменчивость запасов должна быть достоверно ниже, чем в генеральной совокупности. Для стратификации используются таксационные характеристики выделов последнего лесоустройства. При выделении страт применяется Единая схема стратификации лесов Российской Федерации. Лесные страты формируются с учётом следующих характеристик (критериев стратификации): породы (группы пород), группы возраста и уровня производительности (классов бонитета) насаждений. В зависимости от этих характеристик Методическими рекомендациями предусмотрено выделение 49 страт [1].

В методических рекомендациях по проведению ГИЛ предусмотрено определение количества пробных площадей по объекту работ на основе изменчивости запасов и установленной целевой точности определения общего запаса по данному объекту с использованием следующего уравнения:

$$
\mathrm{N}=\frac{\mathrm{S}^{2} * \mathrm{t}^{2}}{(\mathrm{x} * \mathrm{~g})^{2}},
$$

где $\mathrm{N}$ - количество пробных площадей по страте в пределах лесопарков, шт.;

$\mathrm{s}^{2}-$ дисперсия запасов древесины;

$\mathrm{t}$-значение критерия Стьюдента (1,96 с вероятностью 0,95);

$\mathrm{x}$ - среднее значение запаса древесины, $\mathrm{M}^{3} / \mathrm{ra}$;

$\mathrm{g}$ - целевая точность (0...1).

Среднее значение (х) рассчитывается по формуле

$$
\mathrm{x}=\Sigma \mathrm{x}_{\mathrm{i}} * \mathrm{a}_{\mathrm{i}} / \Sigma \mathrm{a}_{\mathrm{i}},
$$

где $\mathrm{x}_{\mathrm{i}}$ - запас выдела на гектаре, $\mathrm{m}^{3} /$ га; $\mathrm{a}_{\mathrm{i}}$ - площадь выдела, га. 
Дисперсия запасов $\left(\mathrm{s}^{2}\right)$ при простой выборке определяется по формуле

$$
\mathrm{s}^{2}=1 / \mathrm{n}-1 * \Sigma\left(\mathrm{x}_{\mathrm{i}}-\mathrm{x}\right)^{2} * \mathrm{w}_{\mathrm{i}},
$$

где $\mathrm{n}$ - количество выделов;

$\mathrm{w}_{\mathrm{i}}$ - вес выдела.

Вес выдела $\left(\mathrm{w}_{\mathrm{i}}\right)$ устанавливается по соотношению площадей выделов по формуле

$$
\mathrm{w}_{\mathrm{i}}=\mathrm{a}_{\mathrm{i}} * \mathrm{n} / \Sigma \mathrm{a}_{\mathrm{i}} \text {. }
$$

В нашей работе количество пробных площадей определялось дифференцированно по выделенным стратам.

Объектом исследований явились насаждения 15 лесопарков, находящихся в областной собственности. Они представляют собой так называемое «зелёное кольцо» города и занимают площадь 12094,8 га. Лесопарки существенно различаются по площади, таксационной структуре произрастающих на их территории лесных насаждений и уровню техногенных нагрузок [5].

\section{Результаты исследования и их обсуждение}

В основу исследований положены материалы лесоустройства 2008 г. Площади всех 15 лесопарков по данным лесоустройства приведены в табл. 1.

Данные табл. 1 свидетельствуют, что лесопарки МО «город Екатеринбург» существенно различаются по площади. Самым крупным является лесопарк Южный. Его площадь составляет 2167 га (17,9\% от общей площади лесопарков города). В то же время площадь Мало-Истокского лесопарка занимает всего 11 га (0,1\%).
В соответствии с Единой схемой стратификации лесов Российской федерации лесные насаждения лесопарков корректно группируются в 29 лесных страт. Причём наибольшая площадь (3995,7 га) приходится на 10 лесную страту, которая объединяет светлохвойные спелые и перестойные высокопроизводительные (I-II классов бонитета) насаждения. Второе место по площади (1446,5 га) занимает 11 страта, в которую сгруппированы светлохвойные спелые и перестойные среднепроизводительные (III$\mathrm{V}$ классов бонитета) насаждения. Примерно одинаковыми площадями характеризуются 4 (1044,2 га) и 37 (1081,5 га) страты. Причем 4 страта объединяет светлохвойные средневозрастные высокопроизводительные насаждения, а 37 - мелколиственные спелые и перестойные высокопроизводительные. Общая площадь остальных 25 выделенных в лесопарках города лесных страт составляет 4818,1 га. Более детально распределение площадей насаждений лесопарков по лесным стратам показано на рисунке.

В целом приведённые материалы свидетельствуют, что в лесопарках города по площади доминируют хвойные виды, а среди них сосна. Преобладают насаждения высокой производительности (2 класс бонитета и выше). Возрастная структура лесопарков далека от оптимальной. Она характеризуется существенным накоплением спелых и перестойных насаждений. Данное обстоятельство косвенно свидетельствует о низкой устойчивости лесопарковых насаждений.

Площади лесопарков МО «город Екатеринбург»

Таблица 1

\begin{tabular}{|l|c|c|}
\hline \multirow{2}{*}{ Лесопарк } & \multicolumn{2}{|c|}{ Площадь } \\
\cline { 2 - 3 } & \multicolumn{2}{c|}{ га } \\
\hline Железнодорожный & 1099,4 & 4,3 \\
\hline Калиновский & 517,8 & 9,1 \\
\hline Карасье-Озерский & 882,6 & 4,3 \\
\hline Им. лесоводов России & 11 & 0,1 \\
\hline Мало-Истокский & 336 & 2,8 \\
\hline Московский & 1586,4 & 13,1 \\
\hline Нижне-Исетский & 642,5 & 5,3 \\
\hline Оброшинский & 498,1 & 4,1 \\
\hline Санаторный & 415 & 3,4 \\
\hline Уктусский & 97 & 0,8 \\
\hline Лесной парк культуры и отдыха им. Маяковского & 726 & 6 \\
\hline Шарташский & 2012 & 16,6 \\
\hline Шувакишский & 588 & 4,9 \\
\hline Юго-западный & 2167 & 17,9 \\
\hline Южный & 12094,8 & 100 \\
\hline Итого & & \\
\hline
\end{tabular}



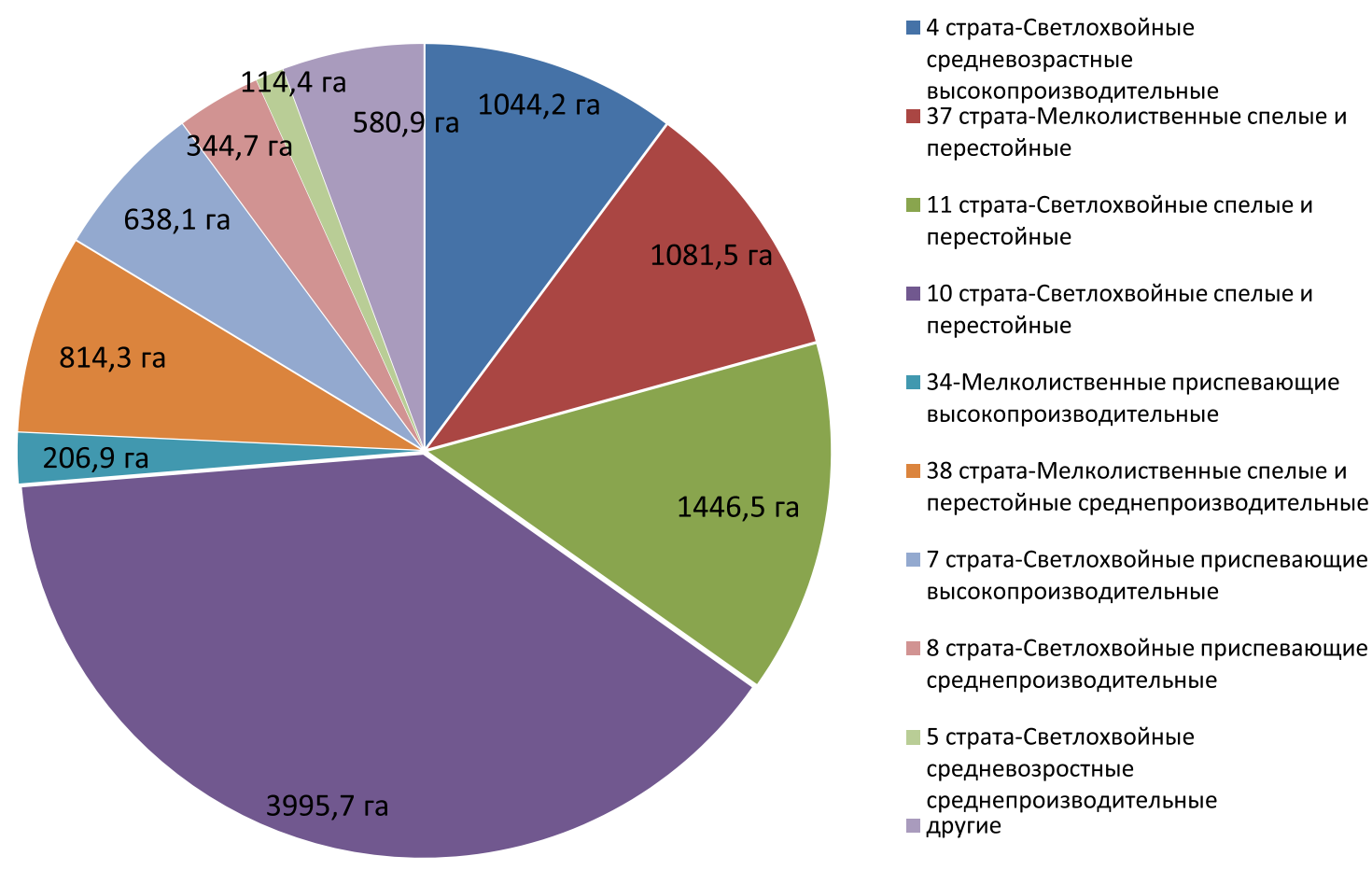

Распределение площуадей насаждений лесопарков по лесным стратам

Ход исследований по определению количества пробных площадей рассмотрим на примере четырёх основных лесных страт $(4,10,11$ и 37$)$, на долю которых приходится более $62 \%$ от общей площади лесопарков. С этой целью по каждой из страт с использованием повыделенной базы лесоустроительных данных проводилась оценка изменчивости запасов насаждений. Основные статистические показатели распределения запасов насаждений в указанных лесных стратах представлены в табл. 2.

Данные табл. 2 свидетельствуют, что наиболее продуктивными являются насаждения 10 страты. В данной страте максимальный запас составляет $590 \mathrm{~m}^{3}$, а средний $-375 \mathrm{~m}^{3}$ Высокими запасами отличаются и насаждения 4 и 11 страт. В 37 страте запасы не столь значительны, что вполне логично. В этой страте преобладают березовые насаждения.

Наибольшая изменчивость запасов насаждений характерна для 37 страты (коэффициент вариации составляет 27,8\%), а наименьшая - для 10 (19,9\%). В целом следует признать изменчивость запасов во всех рассматриваемых стратах невысокой. В специальной литературе лесные массивы, в которых вариация запасов насаж- дений менее $35 \%$, рекомендуют относить к очень однородным. По величине коэффициента вариации запасов выделяют 5 групп лесных массивов: очень однородные (коэффициент вариации $35 \%$ и менее), однородные (36-55\%), средние по однородности (56-75\%), неоднородные (76-95\%) и очень неоднородные (96\% и более).

Лесопарки на территории МО «город Екатеринбург» территориально обособлены. Поэтому представляет интерес анализ однородности выделяемых страт (по запасам насаждений) в пределах конкретных лесопарков. Такие исследования нами проведены на примере пяти лесопарков (Железнодорожного, Калиновского, имени лесоводов России, Московского и Шарташского), расположенных в разных частях города и существенно отличающихся условиями произрастания насаждений. Результаты исследований представлены в табл. 3.

Анализ приведённых в табл. 3 данных позволяет отметить следующее. По всем четырём лесным стратам наибольшей продуктивностью характеризуются насаждения в Московском лесопарке. Насаждения 4 и 10 страт наименьшие запасы имеют в Калиновском лесопарке, а 11 и $37-$ в Шарташском. Обращают на себя вни- 
мание существенные различия между лесопарками по запасам насаждений одних и тех же страт. Так, по четвертой страте средний запас насаждений в Московском лесопарке $\left(407 \mathrm{~m}^{3}\right)$ на 153 м $^{3}$ больше, чем в Калиновском $\left(254 \mathrm{~m}^{3}\right)$. Различия между этими лесопарками по запасам насаждений 10 страты составляют $121 \mathrm{M}^{3}$. При сопоставлении средних запасов насаждений Московского и Шарташского лесопарков по 11 и 37 стратам получаются примерно такие же результаты. На наш взгляд, такое положение главным образом объясняется различиями лесопарков по средней полноте насаждений.

Анализ коэффициентов вариации, приведённых в табл. 3, показывает, что однородность лесных страт по запасам насаждений существенно различается по исследуемым лесопаркам. Наиболее однородны выделенные лесные страты в Железнодорожном и Московском лесопарках, а наименее - в Калиновском. В целом приведённые материалы свидетельствуют в пользу расчёта количества пробных площадей по каждой страте отдельно для каждого лесопарка.

Статистические показатели распределения запасов в лесных стратах

\begin{tabular}{|l|c|c|c|c|}
\hline \multirow{2}{*}{ Основные статистические показатели } & \multicolumn{3}{|c|}{ Страты } \\
\cline { 2 - 5 } & 4 страта & 10 страта & 11 страта & 37 страта \\
\hline Среднее значение запаса на 1 га, ${ }^{3}$ & 346 & 375 & 295 & 319 \\
\hline Стандартная ошибка & 3,5 & 2,2 & 2,9 & 2,6 \\
\hline Медиана & 330 & 360 & 290 & 220 \\
\hline Мода & 300 & 400 & 290 & 250 \\
\hline Стандартное отклонение & 84,6 & 73,1 & 70,8 & 60,9 \\
\hline Дисперсия выборки & 7160 & 5355 & 5009 & 3720 \\
\hline Минимальное значение запаса на 1 га & 110 & 140 & 100 & 50 \\
\hline Максимальное значение запаса на 1 га & 550 & 590 & 500 & 380 \\
\hline Коэффициент вариации, \% & 25,9 & 19,9 & 25,4 & 27,8 \\
\hline
\end{tabular}

Статистические показатели распределения запасов

Таблица 3 в лесных стратах в разрезе лесопарков

\begin{tabular}{|c|l|c|c|c|c|c|}
\hline Страта & \multicolumn{1}{|c|}{ Лесопарк } & $\begin{array}{c}\text { Среднее } \\
\text { значение }\end{array}$ & $\begin{array}{c}\text { Дисперсия } \\
\text { выборки }\end{array}$ & $\begin{array}{c}\text { Минимальное } \\
\text { значение }\end{array}$ & $\begin{array}{c}\text { Максимальное } \\
\text { значение }\end{array}$ & $\begin{array}{c}\text { Коэффициент } \\
\text { вариации, } \%\end{array}$ \\
\hline \multirow{4}{*}{4} & Железнодорожный & 347 & 6019 & 210 & 470 & 22,3 \\
\cline { 2 - 7 } & Калиновский & 254 & 14460 & 110 & 1150 & 47,4 \\
\cline { 2 - 7 } & Лесоводов России & 303 & 11905 & 110 & 460 & 36,1 \\
\cline { 2 - 7 } & Московский & 407 & 5338 & 250 & 500 & 17,9 \\
\cline { 2 - 7 } & Шарташский & 303 & 9767 & 140 & 510 & 32,7 \\
\hline \multirow{4}{*}{10} & Железнодорожный & 406 & 3048 & 280 & 530 & 13,6 \\
\cline { 2 - 7 } & Калиновский & 289 & 9941 & 140 & 520 & 34,5 \\
\cline { 2 - 7 } & Лесоводов России & 387 & 4949 & 250 & 590 & 18,2 \\
\cline { 2 - 7 } & Московский & 410 & 4251 & 250 & 540 & 15,9 \\
\cline { 2 - 7 } & Шарташский & 380 & 4311 & 200 & 500 & 17,3 \\
\hline \multirow{3}{*}{11} & Железнодорожный & 324 & 1728 & 240 & 350 & 12,8 \\
\cline { 2 - 7 } & Калиновский & 285 & 8772 & 110 & 500 & 32,8 \\
\cline { 2 - 7 } & Лесоводов России & 387 & 7279 & 110 & 530 & 22,1 \\
\cline { 2 - 7 } & Московский & 391 & 5982 & 150 & 530 & 19,8 \\
\cline { 2 - 7 } & Шарташский & 272 & 5463 & 120 & 420 & 27,2 \\
\hline \multirow{2}{*}{37} & Железнодорожный & 256 & 3242 & 80 & 340 & 22,3 \\
\cline { 2 - 7 } & Калиновский & 279 & 10975 & 80 & 520 & 37,6 \\
\cline { 2 - 7 } & Лесоводов России & 350 & 10438 & 70 & 510 & 29,2 \\
\cline { 2 - 7 } & Московский & 359 & 7486 & 130 & 540 & 24,1 \\
\cline { 2 - 7 } & Шарташский & 218 & 7157 & 70 & 420 & 38,8 \\
\hline
\end{tabular}


Таблица 4

Характеристика лесных страт и расчётное количество пробных площадей в них

\begin{tabular}{|l|c|c|c|c|c|}
\hline \multicolumn{1}{|c|}{ Страты } & $\begin{array}{c}\text { Площадь } \\
\text { страт, га }\end{array}$ & $\begin{array}{c}\text { Средний } \\
\text { запас, } \text { s }^{3}\end{array}$ & $\begin{array}{c}\text { Количество } \\
\text { выделов } \\
\text { в страте }\end{array}$ & $\begin{array}{c}\text { Дисперсия } \\
\text { Количество } \\
\text { пробных } \\
\text { пледей }\end{array}$ \\
\hline $\begin{array}{l}\text { Светлохвойные средневозрастные высо- } \\
\text { копроизводительные }\end{array}$ & 1044,2 & 346 & 315 & 7628 & 24 \\
\hline $\begin{array}{l}\text { Светлохвойные спелые и перестойные } \\
\text { высокопроизводительные }\end{array}$ & 3995,7 & 375 & 389 & 5926 & 16 \\
\hline $\begin{array}{l}\text { Светлохвойные спелые и перестойные } \\
\text { среднепроизводительные }\end{array}$ & 1442 & 295 & 358 & 5009 & 22 \\
\hline $\begin{array}{l}\text { Мелколиственные спелые и перестойные } \\
\text { высокопроизводительные }\end{array}$ & 1081,5 & 319 & 244 & 3720 & 26 \\
\hline $\begin{array}{l}\text { Мелколиственные приспевающие высо- } \\
\text { копроизводительные }\end{array}$ & 206,9 & 193 & 132 & 3100 & 32 \\
\hline $\begin{array}{l}\text { Мелколиственные спелые и перестойные } \\
\text { средневозрастные }\end{array}$ & 814,3 & 216 & 102 & 12761 & 103 \\
\hline $\begin{array}{l}\text { Светлохвойные приспевающие высоко- } \\
\text { производительные }\end{array}$ & 638,1 & 366 & 255 & 3853 & 11 \\
\hline $\begin{array}{l}\text { Светлохвойные приспевающие средне- } \\
\text { производительные }\end{array}$ & 344,7 & 250 & 195 & 5944 & 37 \\
\hline $\begin{array}{l}\text { Светлохвойные средневозрастные сред- } \\
\text { непроизводительные }\end{array}$ & 114,4 & 232 & 83 & 4558 & 33 \\
\hline Всего & 9681,8 & - & - & - & 304 \\
\hline
\end{tabular}

На данном этапе для определения объёма работ и планирования эксперимента мы ограничились определением необходимого количества пробных площадей в иелом для выделенных в лесопарках города лесных страт. Расчёты проводились по изложенной выше методике с использованием формул (1)-(4). Целевая точность определения запаса принята равной $10 \%$. Использованные при расчётах показатели и итоговое количество пробных площадей по основным лесным стратам приведены в табл. 4. Анализ данных табл. 2 и 4 показывает, что количество пробных площадей по отдельным стратам зависит от их однородности по запасам. Так, для четвёртой страты (светлохвойные средневозрастные высокопроизводительные насаждения) при изменчивости запаса $25,9 \%$ расчётное количество пробных площадей составляет 24 , а для 10 страты (светлохвойные спелые и перестойные высокопроизводительные насаждения) при изменчивости запаса 19,9\% - всего 16. Причем площадь 4 страты почти в четыре раза меньше, чем 10. Лесные страты существенно различаются по средней площади выделов (по стратам она колеблется от 1,4 до 10,3 га), а также по плотности размещения пробных площадей. Например, в 4 страте одна пробная площадь приходится на 43,5 га, в 10 - на 249,7 га, в 11 - на 65,5 га, а в $37-$ на 41,6 га. Такие результаты вполне предсказуемы, когда в алгоритме расчёта пробных площадей не учитывается площадь объекта (страты).

Лесопарки города существенно различаются не только по естественным условиям произрастания насаждений, но и по уровню антропогенных нагрузок. Это обстоятельство требует корректного распределения рассчитанного для той или иной страты количества пробных площадей между лесопарками. Наиболее простым вариантом решения этой задачи является разделение общего количества пробных площадей страты на основе удельного веса лесопарков по площади данной страты. В этом случае количество пробных площадей по страте в пределах конкретного лесопарка можно определить по формуле

$$
\mathrm{N}_{\mathrm{i}}=\mathrm{N}_{\mathrm{c}} * \mathrm{~S}_{\mathrm{ci}} / \mathrm{S}_{\mathrm{c}} \text {, }
$$

где $\mathrm{N}_{\mathrm{i}}$ - количество пробных площадей по страте в пределах лесопарка, шт.;

$\mathrm{N}_{\mathrm{c}}$ - общее количество пробных площадей по страте в объекте исследований, шт.;

$\mathrm{S}_{\mathrm{ci}}$ - площадь страты в пределах лесопарка, га;

$\mathrm{S}_{\mathrm{c}}$ - площадь страты в объекте исследования, га.

Распределение пробных площадей основных лесных страт по пяти лесопаркам показано в табл. 5. 
Таблица 5

Распределение пробных площадей лесных страт по лесопаркам

\begin{tabular}{|c|c|c|c|c|c|c|c|}
\hline \multirow{3}{*}{$\begin{array}{l}\text { № } \\
\text { ח/П }\end{array}$} & \multirow{3}{*}{$\begin{array}{l}\text { Шифр } \\
\text { страты }\end{array}$} & \multicolumn{6}{|c|}{ Количество пробных площадей } \\
\hline & & \multirow[t]{2}{*}{ общее } & \multicolumn{5}{|c|}{ в том числе по лесопаркам } \\
\hline & & & Железнодорожный & Калиновский & $\begin{array}{c}\text { Лесоводов } \\
\text { России }\end{array}$ & Московский & Шарташский \\
\hline 1 & 4 & 24 & 6 & 5 & 3 & 7 & 3 \\
\hline 2 & 10 & 16 & 3 & 1 & 6 & 1 & 5 \\
\hline 3 & 11 & 22 & 2 & 10 & 1 & 2 & 7 \\
\hline 4 & 37 & 26 & 12 & 2 & 3 & 7 & 2 \\
\hline
\end{tabular}

\section{Заключение}

В лесопарках, находящихся под постоянным антропогенным прессом, чрезвычайно актуальной задачей является организация постоянного мониторинга за ростом и состоянием насаждений. Результаты проведенных исследований свидетельствуют, что перспективным подходом при выполнении этой задачи является применение математико-статистических методов, положенных в основу государственной инвентаризации лесов. Выделение лесных страт в соответствии с Единой схемой стратификации лесов Российской Федерации и математико-статистический подход в определении количества пробных площадей и территориальном их размещении позволят проводить мониторинговые и оценочные исследования в лесопарках по единой (сопоставимой) схеме с государственной инвентаризацией лесов. Однако, учитывая роль, функции и месторасположение лесопарков в существующую методику проведения ГИЛ, могут быть внесены изменения, уточняющие и детализирующие мониторинговые исследования, при сохранении основополагающих подходов государственного мероприятия. В частности, для лесопарков актуальна более дифференцированная стратификация насаждений, которую следует проводить с учётом страт, представленных в Единой схеме. Указанные страты в лесопарках необходимо разделить на более однородные части (подстраты) с учётом показателей, определяющих жизненное состояние и экологические функции насаждений. Такими показателями, безусловно, являются полнота, возраст и порода (преобладающая порода). В настоящее время в Единой схеме стратификации лесов Российской Федерации первый показатель не учитывается, а учёт второго производится опосредованно через группы возраста. При стратифи- кации насаждений лесопарков их группировка по возрасту, на наш взгляд, должна проводиться более дифференцированно по классам возраста. Включение в страту насаждений разных пород (например, сосны, лиственницы и кедра) при работе в лесопарках также не совсем корректно. Здесь более обоснованной является стратификация насаждений по преобладающим породам.

\section{Список литературы / References}

1. Методические рекомендации по проведению государственной инвентаризации лесов. Утверждены приказом Рослесхоза от 10.11.2011 № 472. [Электронный ресурс]. URL: http://www.rosleshoz.gov.ru/docs/leshoz/199 (дата обращения: 01.06.2021).

Methodological recommendations for the state forest inventory. Approved by the order of the Federal Forestry Agency of 10.11.2011 No. 472. [Electronic resource]. URL: http:// www.rosleshoz.gov.ru/docs/leshoz/199 (accessed: 01.06.2021). (in Russian).

2. Алексеев А.С. Статистическая инвентаризация лесов в России и современная государственная инвентаризация лесов // Лесной журнал. 2013. № 4. С. 122-124.

Alekseev A.S. Statistical inventory of forests in Russia and modern state inventory of forests // Lesnoy zhurnal. 2013. № 4. P. 122-124. (in Russian).

3. Красиков И.И. Закономерности структуры лесных массивов восточного склона Западного Саяна: автореф. дис. ... канд. сельхоз. наук. Красноярск, 2010. 22 с.

Krasikov I.I. Regularities of the structure of forest massifs of the eastern slope of the Western Sayan: avtoref. dis. ... kand. s.-kh. nauk. Krasnoyarsk, 2010. 22 p. (in Russian).

4. Черных В.Л., Вдовин Е.С., Ворожцов Д.М. Совершенствование методики выборочной таксации запаса древостоев на примере Учебно-опытного лесничества республики Марий Эл // Вестник МарГТУ. 2011. № 1. С. 3-10.

Chernykh V.L., Vdovin E.S., Vorozhtsov D.M., Improving the methodology of selective taxation of the stock of forest stands on the example of the Educational and Experimental forestry of the Republic of Mari El // Vestnik MarGTU. 2011. № . 1. P. 3-10. (in Russian).

5. Метелев Д.В. Структура и динамика городских лесов муниципального образования «город Екатеринбург» и совершенствование организации и ведения хозяйства в них: автореф. дис. ... канд. сельхоз. наук. Екатеринбург, 2020. $20 \mathrm{c}$.

Metelev D.V. Structure and dynamics of urban forests of the municipal formation «the city of Yekaterinburg» and improvement of the organization and management of the economy in them: avtoref. dis. ...kand. s. - kh. nauk. Yekaterinburg, 2020. 20 p. (in Russian). 